\title{
An insight into the sialotranscriptome of the brown dog tick, Rhipicephalus sanguineus
}

\author{
Elen Anatriello ${ }^{1 \dagger}$, José MC Ribeiro ${ }^{3 \dagger}$, Isabel KF de Miranda-Santos ${ }^{1,4}$, Lucinda G Brandão ${ }^{1,5}$, Jennifer M Anderson ${ }^{3}$, \\ Jesus G Valenzuela ${ }^{3}$, Sandra R Maruyama ${ }^{1}$, João S Silva ${ }^{1}$, Beatriz R Ferreira ${ }^{2 *}$
}

\begin{abstract}
Background: Rhipicephalus sanguineus, known as the brown dog tick, is a common ectoparasite of domestic dogs and can be found worldwide. R.sanguineus is recognized as the primary vector of the etiological agent of canine monocytic ehrlichiosis and canine babesiosis. Here we present the first description of a $R$. sanguineus salivary gland transcriptome by the production and analysis of 2,034 expressed sequence tags (EST) from two cDNA libraries, one consctructed using mRNA from dissected salivary glands from female ticks fed for 3-5 days (early to mid library, RsSGL1) and the another from ticks fed for 5 days (mid library, RsSGL2), identifying 1,024 clusters of related sequences.
\end{abstract}

Results: Based on sequence similarities to nine different databases, we identified transcripts of genes that were further categorized according to function. The category of putative housekeeping genes contained $\sim 56 \%$ of the sequences and had on average 2.49 ESTs per cluster, the secreted protein category contained $26.6 \%$ of the ESTs and had 2.47 EST's/clusters, while $15.3 \%$ of the ESTs, mostly singletons, were not classifiable, and were annotated as "unknown function". The secreted category included genes that coded for lipocalins, proteases inhibitors, disintegrins, metalloproteases, immunomodulatory and antiinflammatory proteins, as Evasins and Da-p36, as well as basic-tail and $18.3 \mathrm{kDa}$ proteins, cement proteins, mucins, defensins and antimicrobial peptides. Comparison of the abundance of ESTs from similar contigs of the two salivary gland CDNA libraries allowed the identification of differentially expressed genes, such as genes coding for Evasins and a thrombin inhibitor, which were over expressed in the RsSGL1 (early to mid library) versus RsSGL2 (mid library), indicating their role in inhibition of inflammation at the tick feeding site from the very beginning of the blood meal. Conversely, sequences related to cement (64P), which function has been correlated with tick attachment, was largely expressed in the mid library.

Conclusions: Our survey provided an insight into the $R$. sanguineus sialotranscriptome, which can assist the discovery of new targets for anti-tick vaccines, as well as help to identify pharmacologically active proteins.

\section{Background}

The brown dog tick, Rhipicephalus sanguineus, is a cosmopolitan species from the Ixodidae family [1] found on all continents [2]. Although dogs are the most common host for this tick, it has also been found on other animals, such as cats, rabbits, camels, bovines, goats, horses, sheep, bats, reptiles, and ground feeding birds [1], as well as from humans [3]. It transmits two of the

\footnotetext{
* Correspondence: brferrei@usp.br

+ Contributed equally

${ }^{2}$ Department of Maternal and Child and Public Health Nursing, Ribeirão Preto School of Nursing, University of São Paulo, Ribeirão Preto, SP 14049900, Brazil
}

\section{Ciomed Central}

(c) 2010 Anatriello et al; licensee BioMed Central Ltd. This is an Open Access article distributed under the terms of the Creative Commons Attribution License (http://creativecommons.org/licenses/by/2.0), which permits unrestricted use, distribution, and reproduction in any medium, provided the original work is properly cited. most important arthropod borne pathogens of dogs, namely, Ehrlichia canis and Babesia canis [4,5].

The saliva of $R$. sanguineus mediates parasitism through components that modulate the innate and acquired immune response of the host [6,7]. Accordingly, these compounds are of major importance for tick survival, helping it feed and evade host defenses, including hemostatic factors and the inflammatory responses [8]. In order to identify protein families relevant for the tick-host interface, salivary transcriptomes (sialotranscriptomes) and microarray analysis of several Ixodid tick species have been done [9-18]. In addition, this strategy can help the identification of proteins from tick 
saliva that can induce anti-tick resistance and impair or block transmission of tick-borne pathogens [19-22].

Female adult ticks go through a notable succession of changes during feeding and mating. Their body sizes and weights increase gradually as the blood-feeding progresses. During the feeding period their salivary glands undergo a set of qualitative and quantitative alterations in the content of mRNA and protein $[17,18]$. For $R$. sanguineus female ticks, at days 1-3 (i.e., the early phase of feeding) the change of weight and size is very small, while by the 5 th day these parameters are 2 to 3 times greater. After this stage the rapid phase of engorgement (also called late phase) is initiated; the salivary glands start to degenerate and the ticks can reach 50 to 100 times the size they were when unfed. The time taken by females of $R$. sanguineus to complete their engorgement is 7-10 days [3].

In the present work, we analyzed the sialotranscriptome of two $R$. sanguineus cDNA libraries, that included transcripts from salivary glands from female ticks fed for 3-5 or 5 days on dogs. A total of 2,034 high quality expressed sequence tags (ESTs) were analyzed producing 1,024 contigs, of which 910 were derived from only one EST. For functional annotation of the unique transcripts we used the BLASTx, comparing them against nine different databases. The comparison of the abundance of ESTs from each contig of the two libraries allowed identification of some genes that were significantly differentially represented. To our knowledge, this work is the first transcriptome analysis of salivary glands of $R$. sanguineus tick species. Moreover, the characterization of components from tick saliva is likely to be of value in future when designing novel methods for the control of ticks and tick-borne diseases, as well as searching for proteins that may have potential use in medical and veterinary pathologies".

\section{Methods}

\section{Ticks and salivary gland collection}

Ticks were obtained from two laboratory colonies, one from the Ribeirão Preto School of Medicine, University of São Paulo, Ribeirão Preto, SP (FMRP-USP), and the other from the School of Agronomical and Veterinary Sciences, São Paulo State University, Jaboticabal, SP (FCAV-UNESP), both were maintained at $29^{\circ} \mathrm{C}$ in a biochemical oxygen-demand incubator with $85 \%$ relative humidity. Adult ticks (25 females and 25 males) were allowed to feed in plastic feeding chambers glued (Britania Adhesives P4104 Latex, Brentwood, UK) to the back of 1-3 years old female mongrel dogs for either libraries. These dogs were not naïve to ticks, however had no ticks when were tick-infested. Tick infestations were performed at both locations (FCAV-UNESP and FMRPUSP) using four dogs (2 per group). After five days,
25 female ticks were collected and used to construct the RsSGL2 library (FCAV-UNESP), while 10 female ticks fed for 3, 4 and 5 days (summing 30 ticks) were pooled and used to make up the RsSGL1 library (FMRP-USP). Salivary glands (25-30 pairs) were dissected from female ticks and washed in ice-cold phosphate-buffered saline (PBS), pH 7.4 and then incubated in RNAlater solution (Ambion, Austin, USA) for $24 \mathrm{~h}$ at $4^{\circ} \mathrm{C}$ and then stored at $-80^{\circ} \mathrm{C}$ until used.

\section{cDNA library construction and sequencing}

Total mRNA was isolated from $R$. sanguineus salivary glands using the micro Fast Track $^{\mathrm{TM}}$ 2.0 RNA extraction kit (Invitrogen, Carlsbad, USA) according to the manufacturer's protocol. A long distance PCR based cDNA library was constructed in a $\lambda$ TripleEx 2 vector following the procedures from the SMART ${ }^{\mathrm{TM}} \mathrm{cDNA}$ Library Construction Kit (Clontech, Palo Alto, USA). This system utilizes oligoribonucleotide (SMART IV) to attach an identical sequence at the $5^{\prime}$ end of each reverse-transcribed cDNA strand. The sequence was then employed in subsequent PCR reactions and then digested with restriction enzymes. First-strand synthesis was carried out using PowerScript reverse transcriptase at $42^{\circ} \mathrm{C}$ for $1 \mathrm{~h}$ in the presence of the SMART IV and CDS III (3') primers. Second-strand synthesis was performed by a long-distance (LD) PCR-based protocol using Advantage $^{\mathrm{TM}}$ Taq Polymerase (Clontech) mix in the presence of the $5^{\prime}$ PCR primer and the CDS III (3') primer. The cDNA synthesis procedure resulted in the creation of $S f i$ A and B restriction enzyme sites at the ends of the PCR products that are used for cloning into the phage vector.

A small portion of the cDNA obtained by PCR was analyzed on a $1.1 \%$ agarose gel with ethidium bromide $(1.5 \mu \mathrm{g} / \mathrm{mL})$. The optimal number of cycles with visible and equally represented products was used. Doublestranded cDNA was immediately treated with proteinase $\mathrm{K}$ at $45^{\circ} \mathrm{C}$ for $20 \mathrm{~min}$, and the enzyme was removed by ultrafiltration though a Microcon (Amicon Inc., Beverly, USA) YM-100 centrifugal filter device. The cleaned, double-stranded cDNA was then digested with SfiI at $50^{\circ} \mathrm{C}$ for $2 \mathrm{~h}$, followed by size fractionation on a ChromaSpin-1000 column (Clontech).

The cDNA mixture was ligated into the $\lambda$ TriplEx2 vector (Clontech) and the resulting ligation mixture was packaged using the GigaPack ${ }^{\oplus}$ III Plus packaging extract (Stratagene, La Jolla, CA) according to the manufacturer's instructions. The packaged library was plated by infecting log-phase XL1-Blue Escherichia coli cells (Clontech). The percentage of recombinant clones was determined by performing a blue-white selection screening on LB/MgSO4 plates containing X-gal/IPTG. Recombinants were also determined by PCR, using 
vector primers from the SMART ${ }^{\mathrm{mm}}$ cDNA Library Construction Kit (Clontech) and visualizing the products on a $1.1 \%$ agarose gel with ethidium bromide. Random clones were sequenced from the $5^{\prime}$ direction only, because successful sequencing from the 3 ' end was usually lower than $40 \%$. Full length sequences were obtained in selected cases by performing primer-based extension protocols. For details see Francischetti et al. and Valenzuela et al. $[23,24]$.

\section{Bioinformatic tools and statistical tests used}

ESTs were trimmed of primer and vector sequences. The BLASTn [25], CAP3 assembler [26] and ClustalW software [27] were used to compare, assemble, and align high quality ESTs, respectively. For functional annotation of the transcripts we used BLASTx [25] to compare the nucleotide sequences with the non-redundant (NR) protein database of the National Center of Biological Information (NCBI) and to the Gene Ontology (GO) database [28]. The program reverse position-specific BLAST (RPS-BLAST) [25] was used to search for conserved protein domains in the Pfam [29], SMART [30], Kog [31], and conserved domains databases (CDD) [32]. We have also compared the transcripts with a subset of mitochondrial/plastid and rRNA nucleotide sequences downloaded from NCBI and to several organism proteomes downloaded from NCBI, ENSEMBL, or VectorBase. For all comparisons please consult Additional file 1. Segments of the three-frame translations of the EST (as the libraries were unidirectional, six-frame translations were not used) starting with a methionine found in the first 30 predicted amino acids, or the predicted protein translation in the case of complete coding sequences, were submitted to the SignalP server [33] to help identify translation products that could be secreted. $\mathrm{O}$-glycosylation sites on the proteins were predicted with the program NetOGlyc [34].

All sequences reported in this paper are available publicly under the accession numbers GT030184-GT032391 and EZ406035-EZ406256 (EST's from adult female salivary gland cDNA library) at GenBank and are accessible in Additional file 1.

For sequence comparisons and phylogenetic analysis, we retrieved tick sequences from GenBank, as well as deduced protein sequences from ESTs deposited in $\mathrm{dbEST}$, as described and made accessible in a previous review article [8]. Phylogenetic analysis and statistical neighbour-joining (NJ) bootstrap tests of the phylogenies were done using the Mega package [35] after sequence alignment was performed using ClustalX [36].

The individual cDNA libraries were directly compared with each other using a customized program (Count Libraries) that assesses the individual contribution of each library to the combined contig. This analysis is interesting to suggest putative proteins that may be over- or under-represented at a given time point. A Chi-square analysis was used to evaluate the significance level at $p<0.05$ between the number of transcripts in the same contig originating from the two libraries used.

\section{Results and Discussion}

\section{Overview of the assembled salivary EST set}

A total of 2,034 ESTs were used to produce a $R$. sanguineus salivary gland specific transcriptome database (Additional file 1), 875 ESTs from 5 days fed ticks (RsSGL2) and 1,159 from 3 to 5 days fed ticks (RsSGL1), which were assembled yielding 1,024 unique transcripts ("clusters" of related sequences), 910 of which were derived from only one EST (singleton). This large number of singletons contrasts with previous sialotranscriptomes of hematophagous insects and Ixodid ticks, giving an appearance of a "normalized" library.

Manual annotation of the transcripts resulted in seven broad categories of expressed genes (Table 1). The putative housekeeping genes category contained $56 \%$ of the clusters, which had, on average, 2.49 sequences per cluster, the secreted category contained $26.6 \%$ of the clusters which contained $2.47 \mathrm{ESTs}$ /clusters, while $15.3 \%$ of the transcripts, mostly singletons, were not classifiable, constituting the unknown category. The transcripts assigned to the unknown category could represent novel proteins or derive from the less conserved $3^{\prime}$ or $5^{\prime}$ untranslated regions of genes, as was suggested from the sialotranscriptome of Anopheles gambiae [37]. Sequences deriving from Babesia, Anaplasma, Densovirus and transposable elements (TE) accounted for the remaining sequences, mostly singletons. Babesia and densoviralrelated proteins were also described in a previous sialotranscriptome of Ixodes scapularis [13]. Ribosomal proteins, possibly derived from Babesia canis, were found in the RsGLS1 library, and may be useful for diagnostic purposes (Additional file 1). TE related sequences may either indicate the presence of active transposition in the tick, or more likely, the expression of sequences that are able to suppress transposition [38]. Low level

Table 1 Classification and abundance of salivary transcripts

\begin{tabular}{lrrrc}
\hline Class & ESTs & \% & Clusters & ESTs/Cluster \\
\hline Housekeeping & 1138 & 55.95 & 457 & 2.49 \\
Putative secreted & 541 & 26.60 & 219 & 2.47 \\
Unknown & 312 & 15.30 & 306 & 1.02 \\
Babesia & 35 & 1.72 & 34 & 1.03 \\
Transposable elements & 5 & 0.25 & 5 & 1.00 \\
Densoviral protein & 2 & 0.10 & 2 & 1.00 \\
Anaplasma & 1 & 0.05 & 1 & 1.00 \\
\hline Total & 2034 & 100 & 1024 & \\
\hline
\end{tabular}


expression of TE sequences have been a relatively common finding in previously analyzed sialotranscriptomes.

\section{Housekeeping genes}

Ninety-eight transcripts (mostly full-length) comprised of 1,138 ESTs were annotated as housekeeping genes and were further categorized into 20 subgroups according to function (Table 2 and Additional file 1). Transcripts associated with protein synthesis machinery represented $47 \%$ of all transcripts associated with housekeeping function, an expected result due to the secretory nature of the organ. Energy metabolism accounted for $23 \%$ of the transcripts. Eight percent of the transcripts were classified as either 'Hypothetical conserved' or 'Conserved secreted' proteins. These represent highly conserved proteins of unknown function, presumably associated with cellular function yet uncharacterized. This functional distribution is typical and was previously described in other sialotranscriptomes [15,16,39].

\section{Putatively secreted class of expressed genes}

A total of 541 ESTs, assembled into 219 contigs, were associated with putative $R$. sanguineus salivary secreted components (Table 3 and Additional file 1). These include previously known gene families, such as metalloproteases, lipocalins, protease inhibitor domain-containing peptides, immuno-modulators, antimicrobial peptides, basic-tail, and glycine rich peptides. Several other deduced sequences code for putatively secreted proteins but have poor or non-significant sequence

Table 2 Classification of transcripts associated with housekeeping function

\begin{tabular}{|c|c|c|c|c|}
\hline Class & ESTs & $\%$ & Clusters & ESTs/Cluster \\
\hline Protein synthesis machinery & 533 & 46.84 & 94 & 5.67 \\
\hline Metabolism, energy & 262 & 23.02 & 94 & 2.79 \\
\hline Unknown conserved & 92 & 8.08 & 66 & 1.39 \\
\hline Protein modification machinery & 64 & 5.62 & 52 & 1.23 \\
\hline Signal transduction & 32 & 2.81 & 25 & 1.28 \\
\hline Protein export & 28 & 2.46 & 24 & 1.17 \\
\hline Cytoskeletal & 21 & 1.85 & 13 & 1.62 \\
\hline Transcription machinery & 20 & 1.76 & 16 & 1.25 \\
\hline Nuclear regulation & 18 & 1.58 & 15 & 1.20 \\
\hline Proteasome machinery & 15 & 1.32 & 11 & 1.36 \\
\hline Metabolism, carbohydrate & 12 & 1.05 & 10 & 1.20 \\
\hline Metabolism, amino acid & 7 & 0.62 & 7 & 1.00 \\
\hline Transporters/Storage & 7 & 0.62 & 4 & 1.75 \\
\hline Metabolism, lipid & 6 & 0.53 & 6 & 1.00 \\
\hline Metabolism, free radicals & 6 & 0.53 & 5 & 1.20 \\
\hline Metabolism, dexoxification & 4 & 0.35 & 4 & 1.00 \\
\hline Metabolism, nucleotide & 4 & 0.35 & 4 & 1.00 \\
\hline Metabolism, intermediate & 3 & 0.26 & 3 & 1.00 \\
\hline Extracellular matrix, adhesion & 2 & 0.18 & 2 & 1.00 \\
\hline Transcription factor & 2 & 0.18 & 2 & 1.00 \\
\hline Total & 1138 & 100 & 457 & \\
\hline
\end{tabular}

Table 3 Classification of transcripts that are associated with a secretory function

\begin{tabular}{lcccc}
\hline Class & ESTs & $\%$ & Clusters & $\begin{array}{c}\text { ESTs/ } \\
\text { Cluster }\end{array}$ \\
\hline Other putative secreted & 192 & 35.49 & 103 & 1.86 \\
Lipocalins & 116 & 21.44 & 28 & 4.14 \\
Glycine rich polypeptides & 72 & 13.31 & 23 & 3.13 \\
Protease inhibitor domains & 56 & 10.35 & 29 & 1.93 \\
Antimicrobial peptides & 56 & 10.35 & 5 & 11.20 \\
Immunosuppressors (Evasin/Da- & 25 & 4.62 & 12 & 2.08 \\
p36) & 7 & 1.29 & 7 & 1.00 \\
Metalloproteases & 6 & 1.11 & 1 & 6.00 \\
Aegyptin-like & 3 & 0.55 & 3 & 1.00 \\
Mucins & 2 & 0.37 & 2 & 1.00 \\
Similar to mammal skin proteins & 2 & 0.37 & 2 & 1.00 \\
Possible cuticle or cement & 2 & 0.37 & 2 & 1.00 \\
Similar to Grillus accessory gland & 2 & & & \\
peptide & 2 & 0.37 & 2 & 1.00 \\
Basic tail & 541 & 100 & 219 & \\
\hline Total & & &
\end{tabular}

similarity to other known proteins, or to proteins not previously described in tick sialotranscriptomes [8].

\section{Detailed analysis of the sialome of $R$. sanguineus}

From the sequenced clones, 114 of which code for putative secreted products were meticulously analyzed (Additional file 2). The following presentation is a guide for browsing Additional file 2 .

\section{Putative secreted proteins with presumed or experimentally} validated function

Lipocalins The lipocalin family of proteins is ubiquitous in animals [40]. Its barrel structure makes it suitable to carry small substances within the cavity and the barrel sides can acquire diverse functions [41]. As an example of convergent evolution, this family has been recruited to serve diverse functions in saliva of ticks and triatomine bugs, where they serve as scavengers of agonists of inflammation and hemostasis, such as ADP [42], biogenic amines [43-45], leukotrienes and thromboxane $\mathrm{A}_{2}$ $\left(\mathrm{TXA}_{2}\right)[44,46]$, to carry heme and nitric oxide (NO) [47], anticomplement [48], or anticlotting agents [49]. Typically, dozens of such gene products are found within sialotranscriptomes of ticks and triatomine bugs [8,13,15,16,39,50-52]. Additional file 2 displays 27 lipocalin sequences deduced from the $R$. sanguineus sialotranscriptome, 11 of which are full length. An additional $R$. sanguineus protein sequence similar to tick salivary proteins of $\sim 180$ amino acids is annotated as a possible lipocalin. A circular phylogram of the $R$. sanguineus lipocalin sequences containing more than 100 amino acid obtained in this study (26 sequences) as well as homologous sequences obtained from a recently published tick salivary gland database [8] is shown in 
Figure 1. This phylogram depicts that most of the $R$. sanguineus sequences are dispersed into different clades, which contain sequences from other tick species, suggesting an ancient origin for these genes. Despite this clade dispersion, the phylogram also highlights species specific expansions, as indicated in the clades marked I (Rhipicephalus (Boophilus) microplus expansion, including one $R$. sanguineus sequence and one A. cajennense), III ( $R$. appendiculatus expansion including one $R$. sanguineus and one $R$. microplus sequence), IV (I. scapularis expansion), V ( $R$. sanguineus expansion including one $R$. appendiculatus and one $R$. haemaphysaloides sequence), VI and VII (both with Amblyomma americanum expansions). Other similar expansions can be found by close inspection of Figure 1. These are probably the result of recent gene duplication events [53]. Very few proteins displayed in Figure 1 have been functionally characterized. One of them (RHIAP 8470378) was included in a group of $R$. appendiculatus proteins from clade III, that has been shown to be a scavenger of histamine [54,55]. Interestingly, a $R$. sanguineus sequence named RS-47 is also present in clade III, which suggests it may be a close relative. Rooting with clade III, but lacking significant bootstrap support, the sequence DERRE 18032205, from Dermacentor reticulatus, was shown to be a dual binder of histamine and serotonin [43]. An additional possible function for the noncharacterized lipocalins found in Figure 1, similar to soft ticks and triatomine, may be to bind adenosine nucleotides, $\mathrm{TXA}_{2}$, or leukotrienes.

Protease inhibitors The analysis of the $R$. sanguineus sialotranscriptome revealed several protein sequences containing domains associated with protease inhibitors, such as Kunitz [56], thyropin [57,58] and cystatins [59], as well as unique tick protease inhibitor domains, such as a tick carboxypeptidase inhibitor [60], and a tick antithrombin of the madanin/hirudin like family [61].

Kunitz-domain containing proteins, like the lipocalins, are abundantly found in tick sialotranscriptomes. Eleven deduced protein sequences are shown in Additional file 2 which contain one or two Kunitz domains. The circular phylogram of these sequences resulting from the alignment with other related tick sequences (Figure 2) shows that, similarly to the lipocalin family, $R$. sanguineus has several genes coding for the Kunitz family that congregates, with strong bootstrap support, within multi-specific clades (numbered III, IV, V, VII, VIII and IX in Figure 2). Specific gene expansions are also evident (II for I. scapularis, VI and VIII for A. americanum; and VII for R. sanguineus). Clade I, that lacks any $R$. sanguineus sequence, contains the protein from $A$. haebraeum coded by a gene (gi|40890046) that has been previously characterized as a thrombin inhibitor [62]
(Clade IV, containing the $R$. sanguineus protein named RS-290, also includes a $R$. appendiculatus sequence (gi|57014514) which has been characterized as a tryptase inhibitor [63]. No other protein shown in Figure 2 has been functionally characterized, although additional Kunitz-domain containing proteins from ticks have been identified as inhibitors of blood clotting [64-69] and platelet aggregation, thus possibly can have a role in the tick feeding process.

Cystatins are cysteine proteinase inhibitors [59] and have been described in the sialotranscriptome of $I$. scapularis, two members of which have been characterized as inhibitors of cathepsins $\mathrm{L}$ and $\mathrm{S}$, which play roles in inflammation and immunity [70-72]. These proteins also have been regularly found in sialotranscriptomes of other hard and soft tick species [8]. The R. sanguineus sialotranscriptome contained 3 members of this protein family (Additional file 1). Their role as a cysteine proteinase inhibitor remains to be determined.

Thyropin is a domain found as a repeat in the amino terminal region of human thyroglobulin that is proposed to be an inhibitor of cysteine proteases and binding partners of heparin $[73,74]$. Proteins containing these domains have been reported from other tick sialotranscriptomes [8]. RS-899 is a $R$. sanguineus protein containing 2 thyropin domains, as indicated by its comparison to the Pfam database. No tick thyropins have been functionally characterized to date.

A carboxypeptidase inhibitor, a protein that is rich in cysteins, has been previously reported in $R$. bursa, and postulated to affect fibrinolysis [60,75]. Analysis of our data showed a protein RS-334 that presented match with a carboxypeptidase inhibitor (Additional file 1).

Thrombin inhibitors named madanins were isolated from the tick Haemaphysalis longicornis [61]. A related protein named chimadanin is also a thrombin inhibitor [76]. They have no similarities to other proteins found in the NR database. The $R$. sanguineus sialotranscriptome revealed 4 proteins of this family, one of which has a weak similarity to chimadanin, the others being similar to uncharacterized Amblyomma variegatum proteins annotated as hirudin-like [77], purported to be a thrombin inhibitor, shown by the ability to inhibit human platelet aggregation stimulated by thrombin. Members of this family were also found in deduced proteins of previously published sialotranscriptomes from metastriate, but not prostriate, ticks [8].

The Kazal motif characterizes many serine protease inhibitors that affects several target proteins, such as thrombin and trypsin [78]. Three related putative peptide sequences from the $R$. sanguineus sialotranscriptome (RS-132, RS-359 and RS-827) matched proteins annotated as Kazal-domain, despite the fact that the $R$. sanguineus proteins themselves lack Kazal domain 


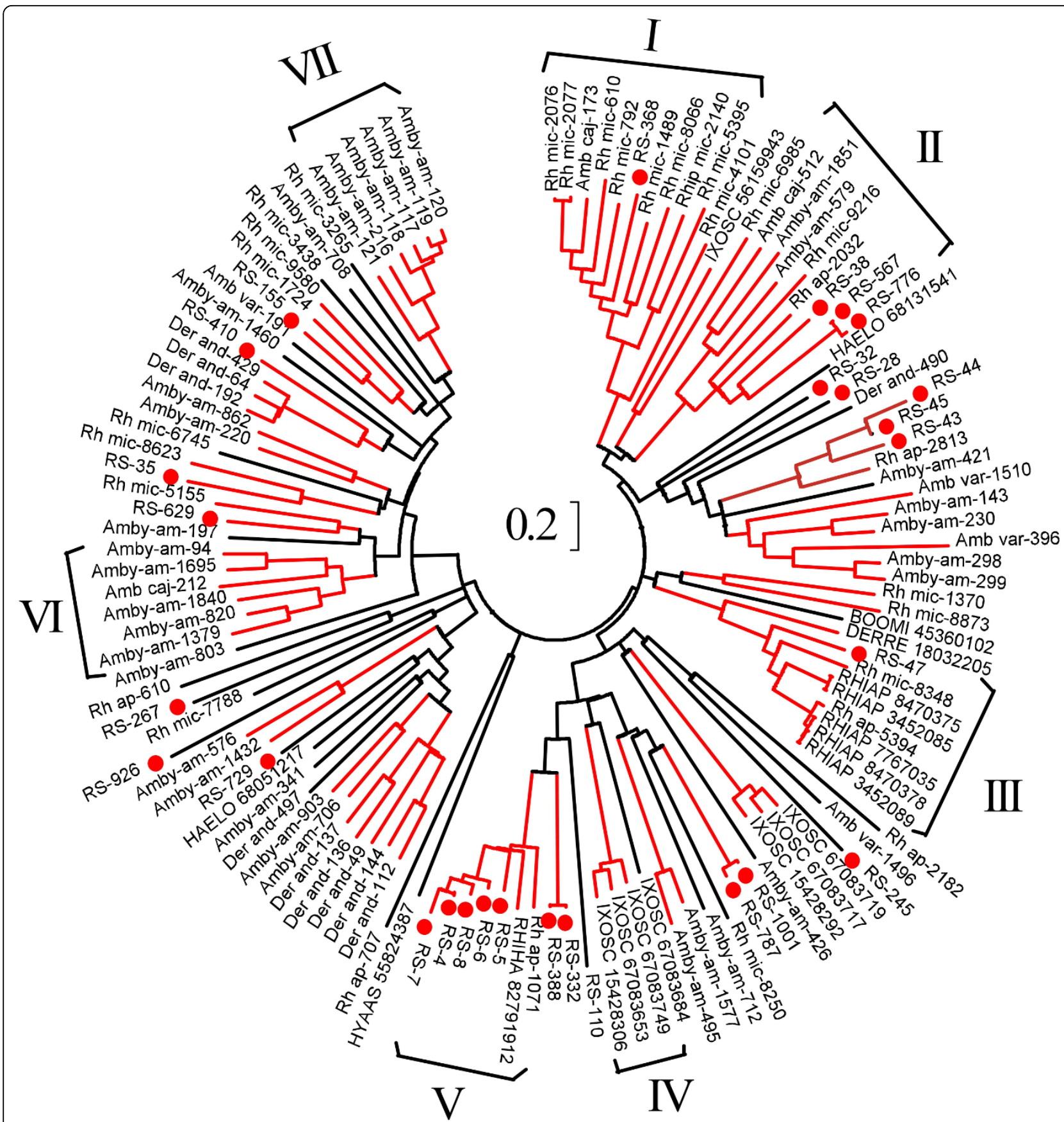

Figure 1 Relationship of Rhipicephalus sanguineus lipocalins to other related tick proteins. The circular phylogram is based on the alignment of sequences derived from this study and similar sequences obtained from the NR database from NCBI, and from tick sequences derived from dbEST. The red branches have bootstrap support above $75 \%$ (10,000 replicates). The bar at the center indicates $20 \%$ amino acid divergence. The $R$. sanguineus sequences are indicated by a circle, and start with RS-. The sequences obtained from the NR database are indicated by 5-6 letters related to the tick species followed by the NCBI accession number. Remaining sequences were deduced from dbEST and are available from Francischetti et al. [8].

signature, as searched by rpsBLAST against the conserved domains database.

The basic tail and $18.3 \mathrm{kDa}$ superfamily The basic tail family (BT) was so named due to a stretch of lysine residues in the carboxytermini of several related salivary proteins of I. scapularis [79]. The cluster of basic amino acids may drive these proteins to negatively charged lipids involved in clotting activation [80,81]. The 18.3 $\mathrm{kDa}$ family was found later to be related to the BT family by PsiBLAST [13]. Although more expanded in 


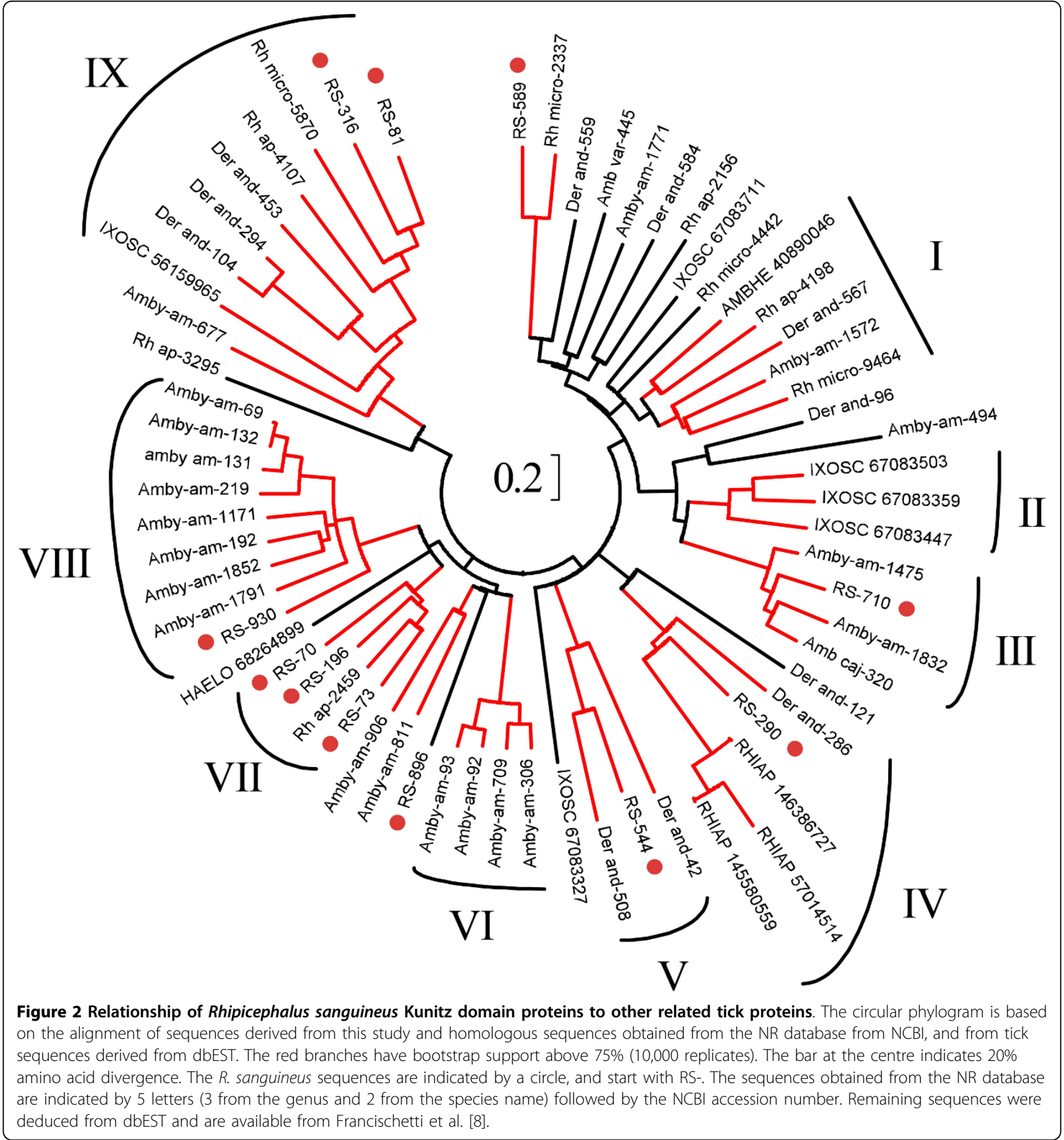

Ixodes, the family is also found in metastriate and argasid ticks [8]. Some proteins of this family in the $I$. scapularis species were characterized as anti-clotting [65]. Four proteins deducted from the R. sanguineus sialotranscriptome are divergent but clearly related. They produce matches to basic tail and $18.3 \mathrm{kDa}$ members. Alignment of these proteins and their matches (Figure $3 \mathrm{~A})$ reveals that one group of proteins has the typical basic tail signature, including RS-329, while a second group of longer sequences belongs to the $18.3 \mathrm{kDa}$ family, and includes the three remaining $R$. sanguineus sequences. This alignment shows only conservation of one Gly and four Cys residues. The phylogram (Figure 3B) can be divided into three groups and six branches. Group I contains the typical Ixodes BT expanded family, with two distinct branches ( $\mathrm{a}$ and $\mathrm{b}$ in Figure 3B). Group II includes metastriate ticks, all containing a BT signature, with two robust clades, represented by 
A
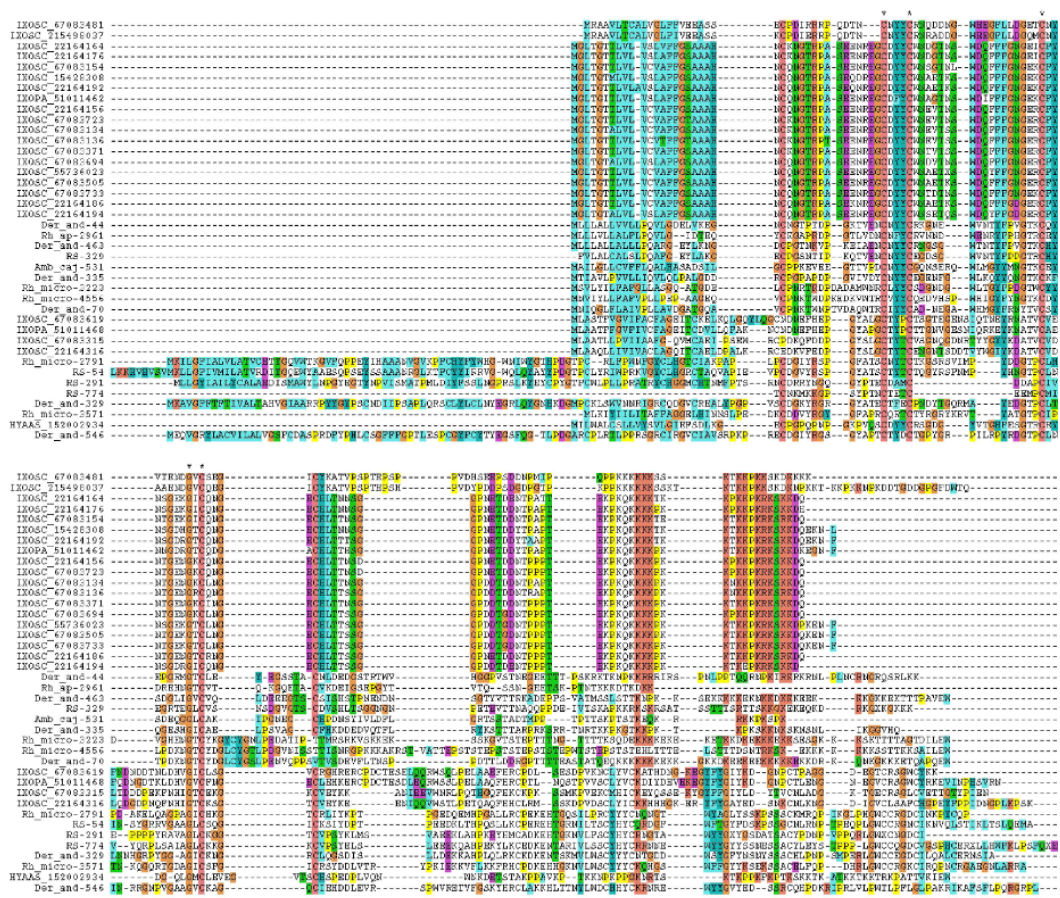

B

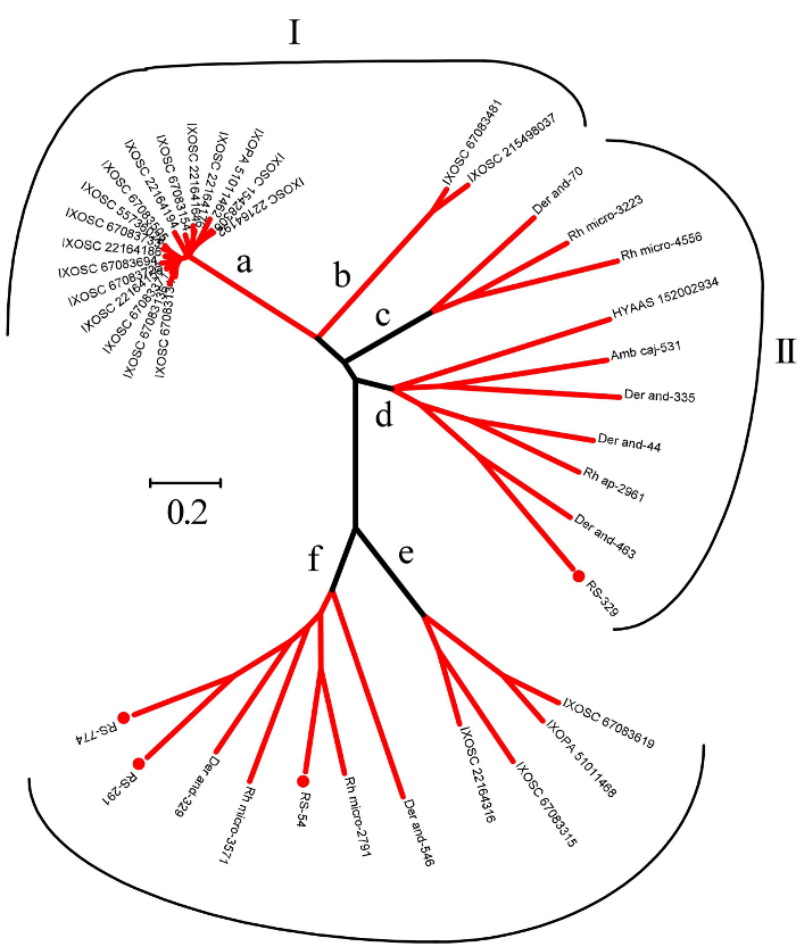

III

Figure 3 The salivary basic tail and $\mathbf{1 8 . 3}$ kDa proteins of Rhipicephalus sanguineus. A) Clustal alignment with other tick proteins. The asterisk $\left(^{*}\right)$ indicates identical amino acids. B) Phylogram of the alignment. The branches shown in red have bootstrap support above $75 \%$. The bar at the centre indicates 20\% amino acid divergence. The $R$. sanguineus sequences are indicated by a circle, and start with RS-. The sequences obtained from the NR database are indicated by 5 letters ( 3 from the genus and 2 from the species name) followed by the NCBI accession number. Remaining sequences were deduced from dbESTand are available from Francischetti et al. [8]. 
branches $\mathrm{c}$ and d (Figure 3B). Group III sequences contain typical $18.3 \mathrm{kDa}$ proteins, in two clades represented by branches e and f, e having only Ixodes and f including only metastriate sequences. The phylogram clearly demonstrates the evolutionary pathways of this divergent protein family among metastriate and prostriate ticks.

Disintegrins The disintegrins contain an Arg-Gly-Asp (RGD) or Arg-Thr-Ser (RTS) triad flanked by cysteines. These peptides, originally discovered in snake venom, bind to platelet integrins that normally attach to fibrinogen and promote platelet aggregation $[82,83]$. The $R$. sanguineus sialotranscriptome reveals two members (RS-325 and RS-609) related to this family. RS-325 codes for a $4.7 \mathrm{kDa}$ peptide that has a typical RGD domain, but no similarity to any other known protein. Acquisition of the RGD motif by proteins of other families has been described in antigen- 5 salivary proteins from tabanids [84], and in Kunitz peptides of ticks [67]. In addition to its affect on host platelet aggregation, disintegrins may also act on several other inflammatory/immune cell features $[85,86]$, which could decrease host cell migration to the tick-feeding lesion. The transcriptome presented herein also displayed a lipocalin (RS-926) that contains a typical RTS domain of the disintegrin family [87], which was not found in any other member of the lipocalin family, suggesting a possible additional function. Similarly, the Kunitz containing proteins RS-316 and RS-589 also each have a RTS and a KTS motif surrounded by cysteines.

Cys-rich peptides associated with metalloproteases Metalloproteases often have extra domains that may interact with matrix proteins [88]. Tick sialotranscriptomes revealed Cys rich proteins that are similar to these extra domains of metalloproteases, including the expanded ixostatin family in I. scapularis and I. pacificus [11,13]. RS-707 codes for a $14.8 \mathrm{kDa}$ mature protein of that is similar to other Cys rich metastriate proteins. Their function has not been characterized.

Immunomodullatory and antiinflammatory proteins Tick saliva has been known to have immunomodulatory activity for decades now [89-91]. More recently, unique proteins have been characterized that act directly on immune cells, or in complexing and annihilating the effect of cytokines [92,93].

Dendritic cells pre-exposed to $R$. sanguineus tick saliva showed reduced migration towards chemokines CCL3 and CCL4 [94]. These results lead to the discovery of the family of Evasin proteins, which are chemokine binding molecules isolated from $R$. sanguineus tick saliva [90] that inhibit inflammation and dendritic cell migration $[95,96]$. Evasin-1 (gi|215275254) binds to chemokines CCL3, CCL4 and CCL18 and corresponds to the contig RS-77 (Additional file 2). Evasin-3 (gi|215275255) binds to chemokines CXCL1 and CXCL8, corresponding to RS-60. Evasin-4 (gi|215275256) binds to chemokines CCL5 and CCL11 and corresponds to RS-909. The $R$. sanguineus sialotranscriptome revealed five additional Evasin sequences (RS-95, RS-119, RS-216, RS-391 and RS-505). These Evasins group into two families, family 1: contains Evasins-1 and -4 and present the conserved block C-x $(14,16)-C-x(3)-C-x(9,18)-C-x(15,18)-Y-x-C-x$

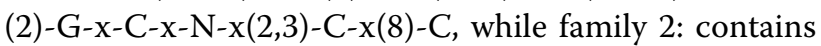
Evasin- 3 and the conserved motif $C-x(3)-C-x(2,5)-G-x$ $(3,4)-C-P-x(1,2)-G-x(0,1)-C-x-C$.

The transcriptome presented herein contained a $3^{\prime}$ truncated protein coded by RS- 255 that matched tick proteins deposited in the NR database annotated as "similar to Da-p36". Da-p36 was isolated from Dermacentor andersoni and the recombinant protein inhibited lymphocyte proliferation [97]. Another immuno-suppressive protein, isolated from H. longicornis, HL-p36, also showed an anti-proliferative cell effect that was related to down-regulation of mRNA levels for IL-2 [98]. The phylogram of the $R$. sanguineus sequence resulting from the alignment with other immunosuppressive tick sequences shows that RS-255 is more closely related to the HL-p36 than to sequences of other ixodid ticks (Figure 4).

Defensins Defensins are ubiquitous peptides with antimicrobial properties $[99,100]$. For ticks, the presence of defensins suggest roles in protection from pathogens. The sialotranscriptome of $R$. sanguineus revealed four divergent members of this family, one of which, as indicated above, contains an RGD motif (Figure 5). RS-82 is similar to other tick defensins, while the remaining are much more divergent; RS-531, for example, was found to be most similar to a wheat defensin.

GY (Gly-Tyr) rich peptides Salivary transcriptomes of haematophagous arthropods, including ticks have revealed the presence of $10 \mathrm{kDa}$ secreted peptides containing multiple GY repeats [51]. Similar peptides in Caenorhabditis elegans were shown to have antimicrobial activity [101]. The $R$. sanguineus sialotranscriptome contained three transcripts coding for peptides containing GY repeats, two of which have less than 60 amino acids and are distantly related (RS-11 and RS-76). They present similarities to tick and worm peptides deposited in the NR database, as well as to several peptides deduced from ESTs present in other tick transcriptomes deposited in dbEST. RS-79 codes for a larger peptide homologous to other GY rich proteins of arthropods, including some annotated as egg-shell proteins. The abundance of Tyr residues may provide for cross linking of these peptides upon phenol oxidase activity. In arthropods, these enzymes participate in sclerotizing the proteins in the flexible exoskeleton after a molt $[102,103]$. 


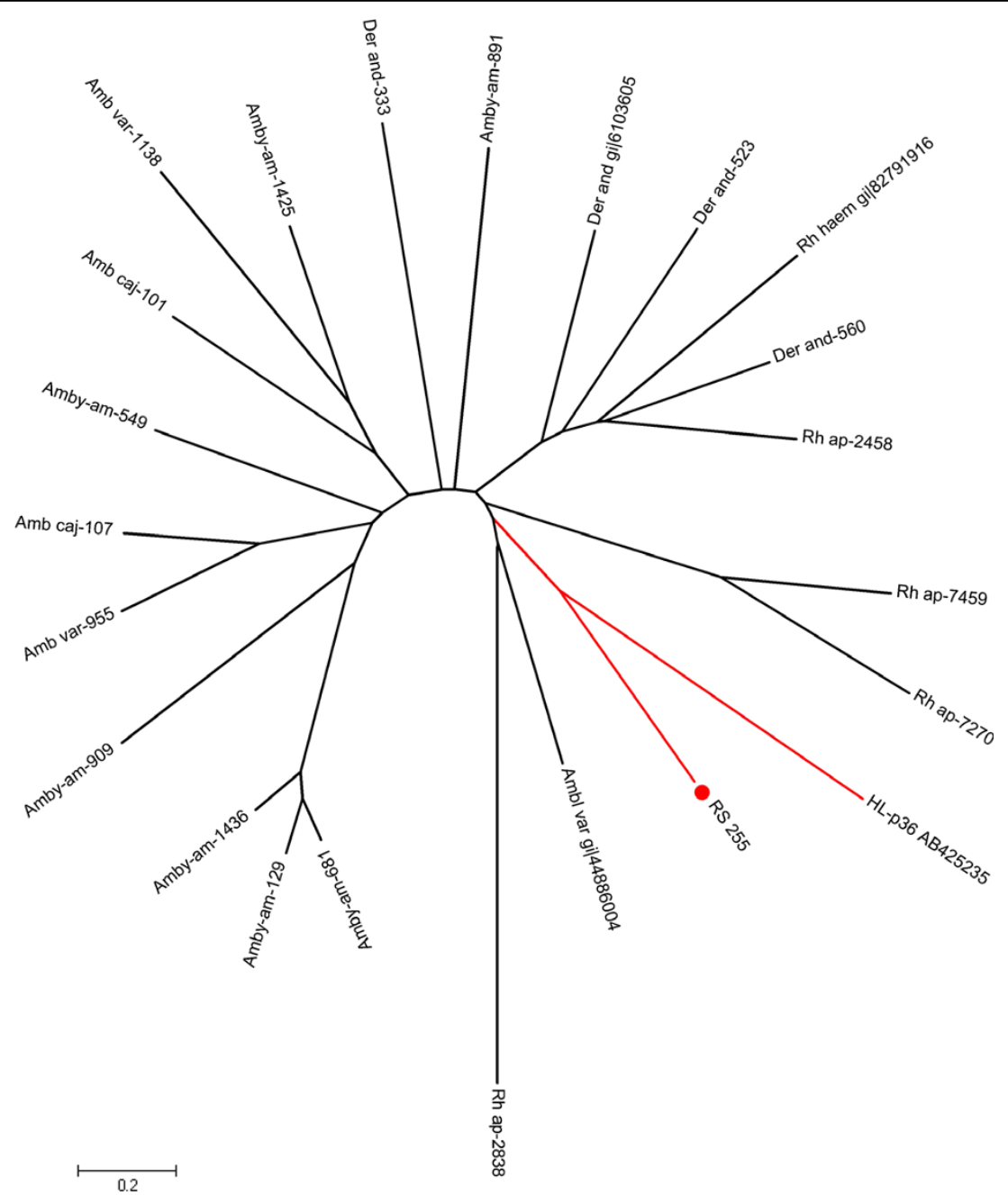

Figure 4 The immunosuppressive protein related to other tick species. The $R$. sanguineus sequence is indicated by a circle, and start with RS-. The remaining sequences were derived from the NR database and are indicated by 5 letter followed by the NCBI accession number. The protein sequences were aligned using the Clustal program and the dendrogram was created using the Mega package after 10,000 bootstrap replicates using the neighbour joining ( $\mathrm{NJ}$ ) algorithm. The bar at the bottom represents $20 \%$ of amino acid substitution. Remaining sequences were deduced from dbEST and are available from Francischetti et al. [8].

Glycine-rich/Cement proteins Ticks attach to their hosts with the help of specialized mouthparts and remain attached by the secretion of cement proteins that glues the mouthparts into the host's skin [104]. Some of these proteins have been characterized and tested as anti-tick vaccines [105-108]. Tick salivary Gly rich proteins are derived from several gene families, some of which are similar to spider fibroin [8]. The $R$. sanguineus sialotranscriptome contained seven full length proteins of this generic family, plus eight fragments (Additional file 1).

Mucin/Perithrophin Mucins are proteins containing galactosylation of Ser or Thr residues, and are normally found associated with mucosal membranes where they 
may play a role in the immune response $[109,110]$. Sialotranscriptomes of ticks and other blood feeding arthropods regularly display such proteins, often with a chitin binding domain that might coat the food canals with a mucous lubricant, in addition to functioning in extracellular matrix adhesion [13,49]. RS-676, similar to arthropod proteins annotated as mucins and peritrophins, contains five putative glycosylation sites near the carboxy terminus and a chitin binding domain (Additional file 2). RS-843 and RS-588 are related proteins with 11 putative glycosylation sites each. These proteins only provide poor matches to other proteins when queried using the program BLASTp against the NR database. Putative secreted proteins with uncharacterized function 8.9 kDa family Sixty members of this protein family have been identified from prostriate and metastriate ticks as described in a recent review [8]. The $R$. sanguineus sialotranscriptome reveals four additional members of this family, identified by sequence comparison to the NR database. Two of these members, RS-17 and RS-864 are closely related to each other. Alignment of selected members of this family shows a conserved group of six cysteine residues, including a doublet at the carboxytermini (Figure 6). Some members of the family have an additional two cysteines. PsiBLAST of members of the $8.9 \mathrm{kDa}$ family against the NR database plus the deduced proteins described in [8] identified Drosophila proteins of similar sizes which have a similar Cys framework, including a doublet at the carboxyterminus. The BLAST link of a
D. melanogaster protein (gi|162951779) is interesting, as it shows various Drosophila proteins, as well as a Culex quinquefasciatus protein that are very similar to a previously described sialoprotein from Aedes albopictus, and also a secreted salivary protein from I. Scapularis, which is a member of the $8.9 \mathrm{kDa}$ family. The function of this protein family in Drosophila is still unknown, as reported by FlyBase [111].

$5.3 \mathrm{kDa}$ family This family of peptides was initially found in I. scapularis, where some members were up regulated in ticks infected with Borrelia burgdorferi, suggesting a role in immune responses to bacteria [13]. Two sequences (RS-968 and RS-402) of the R. sanguineus sialotranscriptome matched with this family.

Metastriate one-of-each family While many tick salivary proteins belong to multi gene families, a previous family, specific to metastriates, was described which appears to have only one member per metastriate species. The $R$. sanguineus sialotranscriptome seems to break this rule by providing evidence for three proteins of this family (RS-757, RS-671 and 935). Alignment of these three proteins with other similar metastriate proteins reveals absolute conservation of two cysteines, one tryptophan, one proline, three glycines and one valine residues, plus several other conserved substitutions (Figure 7). PsiBLAST of the $R$. sanguineus sequences against the NR database with the addition of the deduced tick proteins described before [8] retrieves only hard tick protein, suggesting that this protein family definitely belongs to Ixodidae.

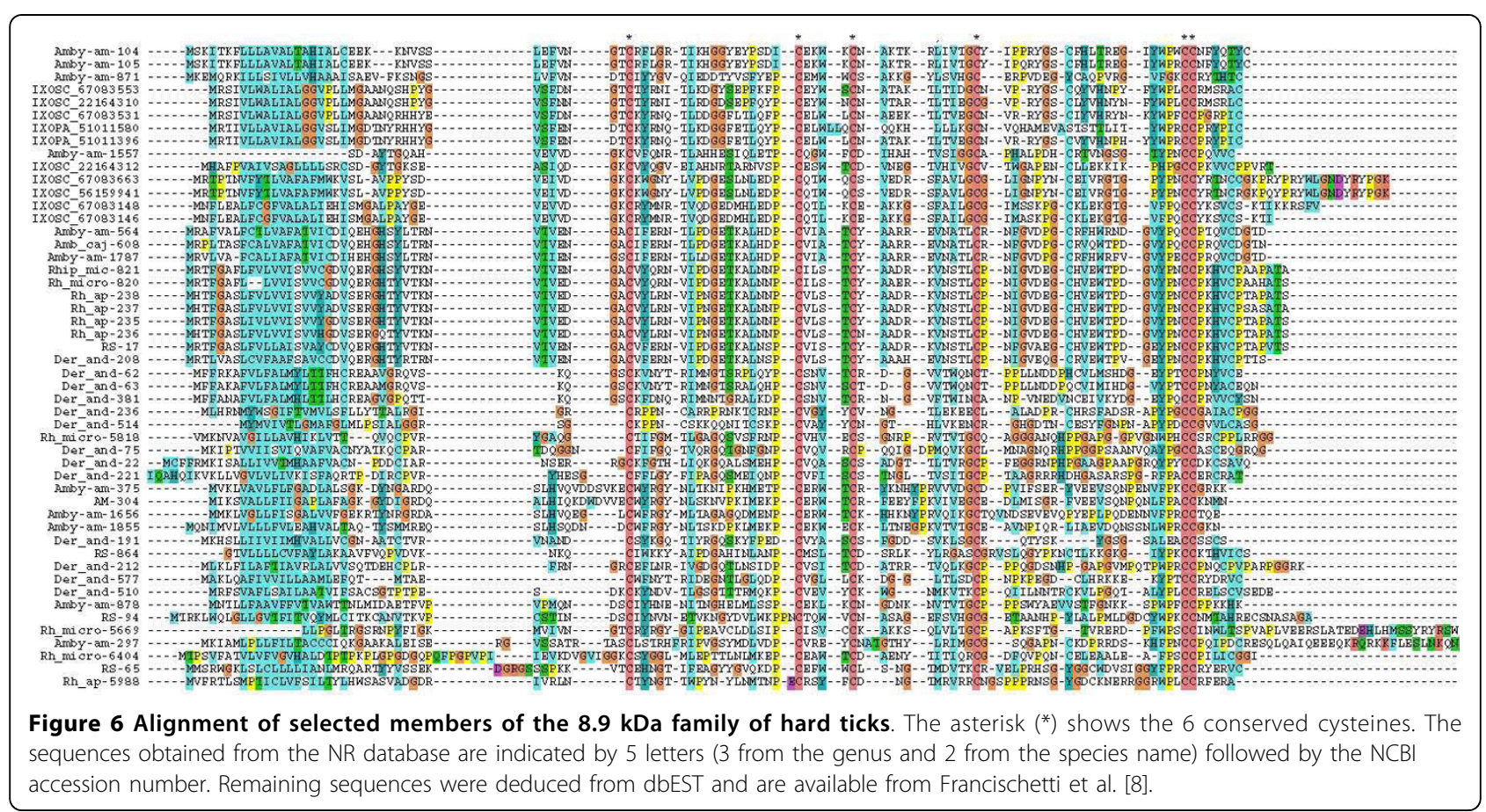




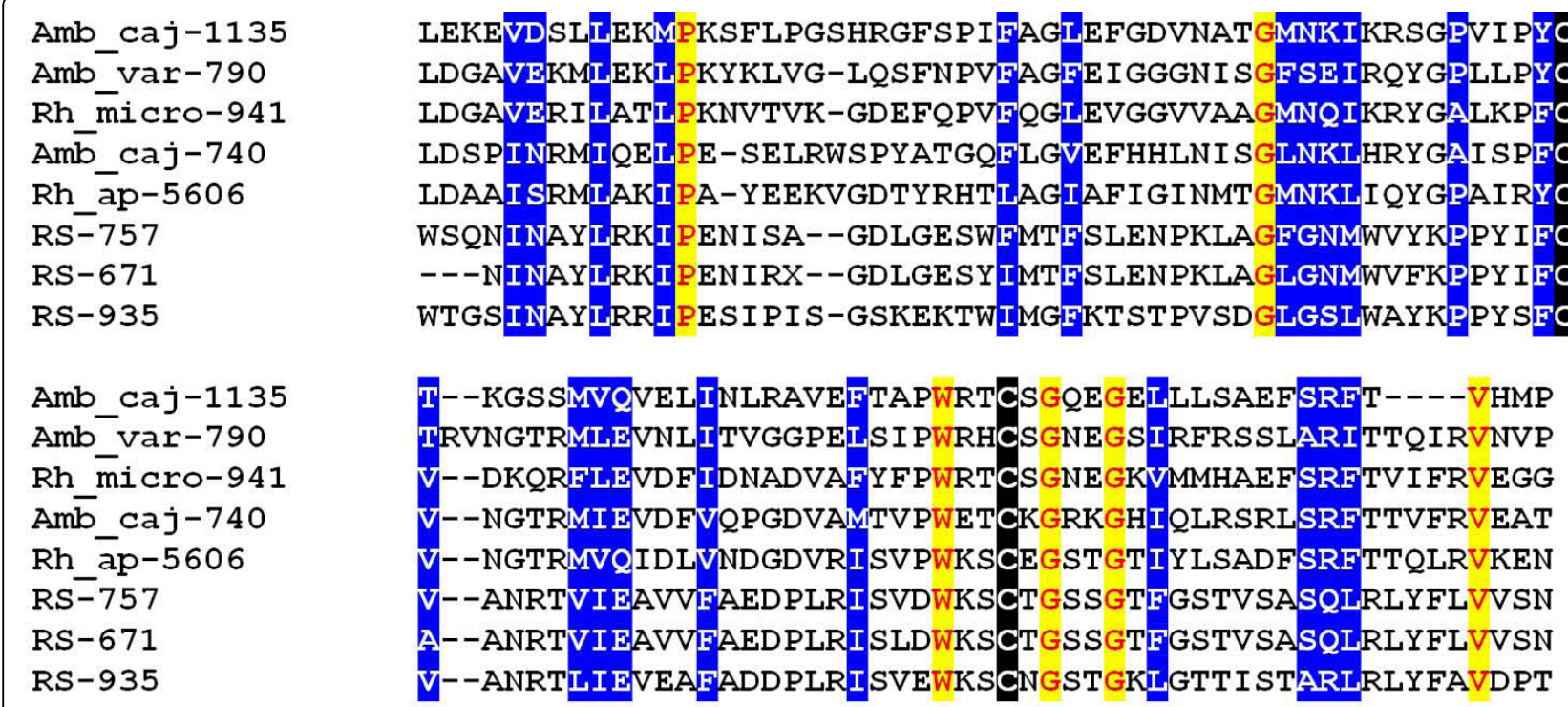

Figure 7 Alignment of the one-of-each family of metastriate proteins. Blocks of identical amino acids are shown in yellow background; conserved cysteines are shown in black background; other conserved amino acids are shown in blue background. Sequences from $R$. $s$ sanguineus start with RS-. Other sequences were obtained from Francischetti et al. [8].

Metastriate acid tail family RS-907 and RS-881 are similar to R. microplus and Amblyomma proteins that have an acidic tail. PsiBLAST of these proteins against the NR plus tick protein data sets recovers only tick proteins thus this appears to be a tick specific protein with unknown function.

Other putative secreted proteins Additional file 2 describes 11 proteins annotated as putative secreted. Some of them match previously described tick proteins that have not been characterized as a protein family due to lack of members in different species. It is possible that they may be recognizable as members of protein families as more transcriptomes/genomes are annotated, or they may represent $R$. sanguineus proteins resulting from genes under accelerated divergent evolution. It should also be noted that some of these proteins may represent annotation artifacts of 3' UTR's, or may represent the truncated carboxyterminus of known proteins, because their membrane domains will often appear as a signal peptide. Additionally, four proteins with putative signal peptide were highly conserved, and accordingly, may represent housekeeping proteins with hormonal or extracellular matrix functions.

\section{Differential expression among the two libraries}

The EST abundance and assembly derived from two libraries, one made of mRNA from ticks feeding for 3-5 days (early to mid library, RsSGL1) and the other from ticks feeding for 5 days (mid library, RsSGL2) is depicted in Additional file 1. Comparison of the abundance of ESTs contributing to each contig in Count
Libraries by chi square analysis allowed for the identification of some genes that are significantly differentially represented among the two libraries.

Among the putative lipocalins, three presented an alternating pattern of expression (Table 4): RS-4 and RS-6, both corresponding to gi82791912, were over expressed in the mid library (with 17 and 12 ESTs in the mid library and only 8 and 1 ESTs in the early to mid library); other putative lipocalins RS-32, corresponding to gi68131541, was over expressed in the early to mid library (no ESTs versus 9). This suggests that the tick possibly relies on an escape mechanism for ligands of its lipocalins throughout the female's blood meal by means of antigenically distinct, but functionally similar proteins. A putative thrombin inhibitor RS-20, was over expressed in the early to mid library (with 16 ESTs derived from the early to mid library and only one from the mid library). This pattern is compatible with a need to suppress coagulation during the initial stages of the blood meal. Unexpectedly, a glycine rich protein RS-23 (64P), similar to cement, was over expressed in the mid library (13 versus 1 EST). This time of expression for a cement protein is peculiar for our libraries, since other work shows down regulation already within four days of tick feeding [112]. A possible explanation can be that this protein has an additional function in this phase, yet this requires more investigation. Regarding the Evasins, differences in expression did not reach significance for any member of this class of immunomodulators. However, as a class, they were expressed more abundantly in the early to mid library (20 versus 5 ESTs). This finding 
Table 4 Differentially expressed transcripts between the RsSGL1 and RsSGL2 cDNA libraries

\begin{tabular}{|c|c|c|c|c|c|c|}
\hline $\begin{array}{l}\text { Number of } \\
\text { Contig }\end{array}$ & $\begin{array}{l}\text { Best match of Over expressed Cluster to NR protein database } \\
\text { Probable secreted class of protein }\end{array}$ & $\begin{array}{c}E \\
\text { value }\end{array}$ & $\begin{array}{l}\text { No of ESTs } \\
\text { RsSGL1 }\end{array}$ & $\begin{array}{l}\text { No of ESTs } \\
\text { RsSGL2 }\end{array}$ & Expected & $\begin{array}{l}p \text { value } \\
\chi^{2} \text { test }\end{array}$ \\
\hline & Protease inhibitor domain-containing & & & & & \\
\hline \multirow[t]{2}{*}{ Contig-20 } & $\begin{array}{l}\text { gi67968373 chimadanin Thrombin inhibitor } \\
\text { [Haemaphysalis longicornis] }\end{array}$ & $\begin{array}{l}3 e- \\
006\end{array}$ & 16 & 1 & 12.85 & 0.00094 \\
\hline & Lipocalins & & & & & \\
\hline Contig-4 & $\begin{array}{l}\text { gi82791912 putative serotonin and histamine binding protein } \\
\text { [Rhipicephalus haemaphysaloides haemaphysaloides] }\end{array}$ & $\begin{array}{l}8 \mathrm{e}- \\
068\end{array}$ & 8 & 17 & 18.90 & 0.00067 \\
\hline Contig-6 & $\begin{array}{l}\text { gi82791912 putative serotonin and histamine binding protein } \\
\text { [Rhipicephalus haemaphysaloides haemaphysaloides] }\end{array}$ & $\begin{array}{l}3 e- \\
067\end{array}$ & 1 & 12 & 9.83 & 0.00087 \\
\hline \multirow[t]{2}{*}{ Contig-32 } & $\begin{array}{l}\text { gi68131541 hypothetical protein } \\
\text { [Haemaphysalis longicornis] }\end{array}$ & $\begin{array}{l}5 e- \\
006\end{array}$ & 9 & 0 & 6.80 & 0.00908 \\
\hline & Glycine rich proteins/other cement related sequences & & & & & \\
\hline \multirow[t]{2}{*}{ Contig-23 } & $\begin{array}{l}\text { gi20069012salivary gland-associated protein 64P } \\
\text { [Rhipicephalus appendiculatus] }\end{array}$ & $\begin{array}{l}2 e- \\
022\end{array}$ & 1 & 13 & 10.58 & 0.00051 \\
\hline & Immunomodullatory-antiinflammatory proteins & & & & & \\
\hline \multirow[t]{2}{*}{ Contig-60 } & gi215275255EVA3_RHISA RecName: Full = Evasin-3 & $\begin{array}{l}1 e- \\
033\end{array}$ & 6 & 0 & 4.53 & 0.03316 \\
\hline & Other putative salivary peptides & & & & & \\
\hline Contig-17 & $\begin{array}{l}\text { gi215497897 secreted protein, putative } \\
\text { [lxodes scapularis] }\end{array}$ & $\begin{array}{l}8 \mathrm{e}- \\
005\end{array}$ & 24 & 5 & 21.93 & 0.00030 \\
\hline Contig-40 & $\begin{array}{l}\text { gi76786687 putative secreted protein } \\
\text { [R. microplus }]\end{array}$ & 0.002 & 8 & 0 & 6.05 & 0.01391 \\
\hline
\end{tabular}

RsSGL1 - salivary gland cDNA library made from female ticks fed for 3-5 days (early to mid library).

RsSGL2 - salivary gland cDNA library made from female ticks fed for 5 days (mid library).

underscores the tick's need to avoid the cellular inflammatory responses triggered by its insults to the skin at the very beginning of the blood meal. This finding is also compatible with the function of Evasins as chemokine-binding proteins. Two genes (RS-17 and RS-40) encoding proteins of unknown function were more abundantly expressed in the early to mid library. There were also mitochondrial products possibly coding for rRNA that were differentially expressed: RS-18 was over expressed early to mid (22 versus 1 EST), while RS-2 was over expressed later (23 versus 0 EST) (Additional file 1). This temporal difference in gene expression was previously described in I. scapularis [13].

\section{Conclusions}

Analysis of the sialotranscriptome of two $R$. sanguineus cDNA libraries, from RsSGL1 and RsSGL2, identified many transcripts coding for different components that can favor the tick in detriment of the host. Some were common to both libraries, such as protein sequences associated with proteases inhibitors, disintegrins with RGD, RST and KTS motifs, immunomodullatory and antiinflammatory proteins, such as Evasins and Dap36, as well as basic tail and $18.3 \mathrm{kDa}$ proteins, mucins, defensins and antimicrobial peptides. An additional phylogenetic analysis indicated conservation between protein families, a phenomenon also found in other tick species, in particular expansion of the lipocalin and Kunitz superfamilies. The phylograms also indicated species specific expansions that probably result from recent gene duplication events, suggested as of important evolutionary adaptive value $[13,113]$. Moreover, the phylogenetic trees depict that most of the $R$. sanguineus sequences are dispersed into different clades, which contain sequences from other tick species, suggesting an ancient origin for these genes. One of the phylogram also clearly demonstrates the evolutionary pathways of $18.3 \mathrm{kDa}$ protein family are divergent among metastriate and prostriate ticks. Furthermore, we found that the transcript RS-255 codes for a sequence closely related to a recently identified transcript found in H. longicornis that codes for a protein that is similar to the immunosuppressant protein Da-p36.

Of interest, we observed that many genes were significantly differentially represented among the early to mid library (RsSGL1) and mid library (RsSGL2). Two transcripts related with lipocalin were over expressed, whereas one was down expressed in the mid library. Thrombin inhibitor and Evasins were over expressed in the early to mid library, while unexpectedly sequences related to cement (64P) were mostly expressed in the mid library. These differences possibly represent adaptations of the tick to the dynamics of the host's antihomeostatic responses to tick feeding. However, mentioned differences require more detailed examination. 
Taken together, these results improve our knowledge of the salivary components of the $R$. sanguineus that can lead to a better understanding of parasite-host interactions, and may originate innovative strategies to find candidate antigens for vaccines, as well as help to discover drugs that could give support to treat coagulopathies and, inflammatory and immunological disorders.

Note: All sequences reported in this paper are available publicly under the accession numbers GT030184GT032391 and EZ406035-EZ406256 (EST's from adult female salivary gland cDNA libraries) at GenBank.

\section{Additional material}

\section{Additional file 1: Hyperlinked Microsoft Excel file with assembled} EST's and various database comparisons. The EST assembly, BLAST, and signal peptide results were loaded into an Excel spreadsheet for manual annotation.

Additional file 2: Hyperlinked Microsoft Excel file with coding sequences and various database comparisons. 114 of which code for putative secreted products were meticulously analyzed in the library of female salivary glands of $R$. sanguineus.

\section{Acknowledgements}

This work was supported by the Intramural Research Program of the Division of Intramural Research, National Institute of Allergy and Infectious Diseases, National Institutes of Health, by the Fundação de Amparo à Pesquisa do Estado de São Paulo - FAPESP (2004/09992-7) and by the Conselho Nacional de Desenvolvimento Científico e Tecnológico - CNPq. E. A. was supported by a scholarship from CNPq (130780/2005-7). The authors thank Dr. G.H. Bechara for the tick specimens used to generate the RsSGL2 library (FCAV-UNESP), and Dr. A.E. Proudfoot and Dr. A. Frauenschuh for some of the ESTs employed in the work. Because J.M.C. Ribeiro is a government employee and this is a government work, the work is in the public domain in the United States. Notwithstanding any other agreements, the $\mathrm{NIH}$ reserves the right to provide the work to PubMedCentral for display and use by the public, and PubMedCentral may tag or modify the work consistent with its customary practices. You can establish rights outside of the U.S. subject to a government use license.

\section{Author details}

${ }^{1}$ Department of Biochemistry and Immunology, Ribeirão Preto School of Medicine, University of São Paulo, Ribeirão Preto, SP 14049-900, Brazil. ${ }^{2}$ Department of Maternal and Child and Public Health Nursing, Ribeirão Preto School of Nursing, University of São Paulo, Ribeirão Preto, SP 14049900 , Brazil. ${ }^{3}$ Laboratory of Malaria and Vector Research, National Institute of Allergy and Infectious Diseases, National Institutes of Health, Bethesda, MD 20892-8132, USA. Embrapa Recursos Genéticos e Biotecnologia, 70770-900, Brasília, DF, Brazil. ${ }^{5}$ Universidade Paulista, Avenida Baguaçu, 1939, 16018-280, Araçatuba, SP, Brasil.

\section{Authors' contributions}

EA, BRF, LGB and SRM constructed and sequenced the libraries; JGV assisted with the strategy of library construction; BRF devised the experimental design for collection of samples; EA and JMA performed the bioinformatic treatment of the sequences; JMR, EA, BRF and IKFMS performed the analyses, including phylogenetic and statistical analyses, and drafted the manuscript; BRF, JSS and IKFMS participated in the study's coordination. All authors read and approved the final manuscript.

Received: 15 December 2009 Accepted: 22 July 2010 Published: 22 July 2010
References

1. Flechtmann CHW: Ácaros de importância médico veterinária. Livraria Nobel S.A., São Paulo 1973, 104.

2. Pegram RG, Clifford CM, Walker JB, Keirans JE: Classification of the Rhipicephalus sanguineus group. (Acari, Ixodoidea, Ixodidae). I. R. sulcatus Neumann, 1908 and R. turanicus Pomerantsev, 1936. Systematic Parasitology 1987, 10:3-26.

3. Walker JB, Keirans JE, Horak IG: The Genus Rhipicephalus (Acari:Ixodidae): A guide to the brown ticks of the world. Cambridge University Press 2000, 643 .

4. Dantas-Torres F, Figueredo LA: Canine babesiosis: a Brazilian perspective. Vet Parasitol 2006, 141:197-203.

5. Dantas-Torres F: The brown dog tick, Rhipicephalus sanguineus (Latreille, 1806) (Acari: Ixodidae): from taxonomy to control. Vet Parasitol 2008, 152:173-185

6. Ferreira BR, Silva JS: Saliva of Rhipicephalus sanguineus tick impairs T cell proliferation and IFN-gamma-induced macrophage microbicidal activity. Vet Immunol Immunopathol 1998, 64:279-293.

7. Ferreira BR, Silva JS: Successive tick infestations selectively promote a T-helper 2 cytokine profile in mice. Immunology 1999, 96:434-439.

8. Francischetti IMB, Sá-Nunes A, Mans BJ, Santos IM, Ribeiro JMC: The role of saliva in tick feeding. Front Biosci 2009, 14:2051-2088.

9. Nene V, Lee D, Kang'a S, Skilton R, Shah T, de Villiers E, Mwaura S, Taylor D, Quackenbush J, Bishop R: Genes transcribed in the salivary glands of female Rhipicephalus appendiculatus ticks infected with Theileria parva. Insect Biochem Mol Biol 2004, 34:1117-1128.

10. Santos IK, Valenzuela JG, Ribeiro JM, de Castro M, Costa JN, Costa AM, da Silva ER, Neto OB, Rocha C, Daffre S, Ferreira BR, da Silva JS, Szabó MP, Bechara GH: Gene discovery in Boophilus microplus, the cattle tick: the transcriptomes of ovaries, salivary glands, and hemocytes. Ann N Y Acad Sci 2004, 1026:242-246.

11. Francischetti IM, My Pham V, Mans BJ, Andersen JF, Mather TN, Lane RS, Ribeiro JM: The transcriptome of the salivary glands of the female western black-legged tick Ixodes pacificus (Acari: Ixodidae). Insect Biochem Mol Biol 2005, 35:1142-1161.

12. Lambson B, Nene V, Obura M, Shah T, Pandit P, Ole-Moiyoi O, Delroux K, Welburn S, Skilton R, de Villiers E, Bishop R: Identification of candidate sialome components expressed in ixodid tick salivary glands using secretion signal complementation in mammalian cells. Insect Mol Biol 2005, 14:403-414.

13. Ribeiro JM, Alarcon-Chaidez F, Francischetti IM, Mans BJ, Mather TN, Valenzuela JG, Wikel SK: An annotated catalog of salivary gland transcripts from Ixodes scapularis ticks. Insect Biochem Mol Biol 2006 36:111-129.

14. Alarcon-Chaidez FJ, Sun J, Wikel SK: Transcriptome analysis of the salivary glands of Dermacentor andersoni Stiles (Acari:Ixodidae). Insect Biochem Mol Biol 2007, 37:48-71.

15. Francischetti IM, Mans BJ, Meng Z, Gudderra N, Veenstra TD, Pham VM, Ribeiro JM: An insight into the sialome of the soft tick, Ornithodorus parkeri. Insect Biochem Mol Biol 2008, 38:1-21.

16. Francischetti IM, Mans BJ, Gudderra N, Hall M, Veenstra TD, Pham VM, Kotsyfakis M: An insight into the salivary transcriptome and proteome of the soft tick and vector of epizootic bovine abortion, Ornithodoros coriaceus. J Proteomics 2008, 71:493-512.

17. Aljamali MN, Ramakrishnan VG, Weng H, Tucker JS, Sauer JR, Essenberg RC: Microarray analysis of gene expression changes in feeding female and male lone star ticks, Amblyomma americanum. Arch Insect Biochem Physiol 2009, 71:236-253.

18. Aljamali MN, Hern L, Kupfer D, Downard S, So S, Roe BA, Sauer JR, Essenberg RC: Transcriptome analysis of the salivary glands of the female tick Amblyomma americanum (Acari: Ixodidae). . Insect Mol Biol 2009, 18:129-154.

19. Mulenga A, Sugimoto C, Sako Y, Ohashi K, Musoke A, Shubash M Onuma M: Molecular characterization of a Haemaphysalis longicornis tick salivary gland-associated 29-kilodalton protein and its effect as a vaccine against tick infestation in rabbits. Infect Immun 1999, 67:1652-8.

20. Wikel SK: Tick modulation of host immunity: an important factor in pathogen transmission. Int J Parasitol 1999, 29:851-859.

21. Nuttall PA, Paesen GC, Lawrie $\mathrm{CH}$, Wang $\mathrm{H}$ : Vector-host interactions in disease transmission. J Mol Microbiol Biotechnol 2000, 2:381-386. 
22. Willadsen P: Tick control: thoughts on a research agenda. Vet Parasitol 2006, 138:161-168.

23. Francischetti IM, Valenzuela JG, Pham VM, Garfield MK, Ribeiro JM: Toward a catalog for the transcripts and proteins (sialome) from the salivary gland of the malaria vector Anopheles gambiae. J Exp Biol 2002, 205:2429-2451

24. Valenzuela JG, Pham VM, Garfield MK, Francischetti IM, Ribeiro JMC: Toward a description of the sialome of the adult female mosquito Aedes aegypti. Insect Biochem Mol Biol 2002, 32:1101-1122.

25. Altschul SF, Madden TL, Schaffer AA, Zhang J, Zhang Z, Miller W, Lipman DJ: Gapped BLAST and PSI-BLAST: a new generation of protein database search programs. Nucleic Acids Res 1997, 25:3389-3402.

26. Huang X, Madan A: CAP3: A DNA sequence assembly program. Genome Res 1999, 9:868-877.

27. Thompson JD, Gibson TJ, Plewniak F, Jeanmougin F, Higgins DG: The CLUSTAL_X windows interface: flexible strategies for multiple sequence alignment aided by quality analysis tools. Nucleic Acids Res 1997, 25:4876-4882.

28. Ashburner M, Ball CA, Blake JA, Botstein D, Butler H, Cherry JM, Davis AP, Dolinski K, Dwight SS, Eppig JT, Harris MA, Hill DP, Issel-Tarver L, Kasarskis A, Lewis S, Matese JC, Richardson JE, Ringwald M, Rubin GM, Sherlock G: Gene ontology: tool for the unification of biology. The Gene Ontology Consortium Nat Genet 2000, 25:25-29.

29. Bateman A, Birney E, Durbin R, Eddy SR, Howe KL, Sonnhammer EL: The Pfam protein families database. Nucleic Acids Res 2000, 28:263-266.

30. Letunic I, Goodstadt L, Dickens NJ, Doerks T, Schultz J, Mott R, Ciccarelli F, Copley RR, Ponting CP, Bork P: Recent improvements to the SMART domain-based sequence annotation resource. Nucleic Acids Res 2002, 30:242-244.

31. Tatusov RL, Fedorova ND, Jackson JD, Jacobs AR, Kiryutin B, Koonin EV, Krylov DM, Mazumder R, Mekhedov SL, Nikolskaya AN, Rao BS, Smirnov S, Sverdlov AV, Vasudevan S, Wolf YI, Yin JJ, Natale DA: The COG database: an updated version includes eukaryotes. BMC Bioinformatics 2003, 4:41.

32. Marchler-Bauer A, Panchenko AR, Shoemaker BA, Thiessen PA, Geer LY, Bryant SH: CDD: a database of conserved domain alignments with links to domain three-dimensional structure. Nucleic Acids Res 2002, 30:281-283.

33. Nielsen $\mathrm{H}$, Engelbrecht J, Brunak S, von Heijne G: Identification of prokaryotic and eukaryotic signal peptides and prediction of their cleavage sites. Protein Eng 1997, 10:1-6.

34. Julenius K, Molgaard A, Gupta R, Brunak S: Prediction, conservation analysis, and structural characterization of mammalian mucin-type Oglycosylation sites. Glycobiology 2005, 15:153-164.

35. Kumar S, Tamura K, Nei M: MEGA3: Integrated software for Molecular Evolutionary Genetics Analysis and sequence alignment. Brief Bioinform 2004, 5:150-163.

36. Jeanmougin F, Thompson JD, Gouy M, Higgins DG, Gibson TJ: Multiple sequence alignment with Clustal X. Trends Biochem Sci 1998, 23:403-405.

37. Arcà B, Lombardo F, Valenzuela LG, Francischetti IM, Marinotti $\mathrm{O}$, Coluzzi M, Ribeiro JM: An updated catalogue of salivary gland transcripts in the adult female mosquito, Anopheles gambiae. J Exp Biol 2005, 208:3971-3986.

38. Wang $X$, Ribeiro JM, Broce AB, Wilkerson MJ, Kanost MR: An insight into the transcriptome and proteome of the salivary gland of the stable fly, Stomoxys calcitrans. Insect Biochem Mol Biol 2009, 39:607-614.

39. Santos A, Ribeiro JM, Lehane MJ, Gontijo NF, Veloso AB, Sant'Anna MR, Nascimento Araujo R, Grisard EC, Pereira MH: The sialotranscriptome of the blood-sucking bug Triatoma brasiliensis (Hemiptera, Triatominae). Insect Biochem Mol Biol 2007, 37:702-712.

40. Flower DR, North AC, Sansom CE: The lipocalin protein family: structural and sequence overview. Biochim Biophys Acta 2000, 1482:9-24.

41. Schlehuber S, Skerra A: Lipocalins in drug discovery: from natural ligandbinding proteins to "anticalins". Drug Discov Today 2005, 10:23-33.

42. Francischetti IM, Andersen JF, Ribeiro JM: Biochemical and functional characterization of recombinant Rhodnius prolixus platelet aggregation inhibitor 1 as a novel lipocalin with high affinity for adenosine diphosphate and other adenine nucleotides. Biochemistry 2002, 41:3810-3818

43. Sangamnatdej S, Paesen GC, Slovak M: A high affinity serotonin- and histamine-binding lipocalin from tick saliva. Insect Mol Biol 2002, 11:79-86.
44. Mans BJ, Ribeiro JM: Function, mechanism and evolution of the moubatin-clade of soft tick lipocalins. Insect Biochem Mol Biol 2008, 38:841-52.

45. Mans BJ, Ribeiro JM, Andersen JF: Structure, function, and evolution of biogenic amine-binding proteins in soft ticks. J Biol Chem 2008, 283:18721-18733.

46. Mans BJ, Ribeiro JM: A novel clade of cysteinyl leukotriene scavengers in soft ticks. Insect Biochem Mol Biol 2008, 38:862-870.

47. Andersen JF, Gudderra NP, Francischetti IM, Ribeiro JM: The role of salivary lipocalins in blood feeding by Rhodnius prolixus. Arch Insect Biochem Physiol 2005, 58:97-105.

48. Nunn MA, Sharma A, Paesen GC, Adamson S, Lissina O, Willis AC, Nuttall PA: Complement inhibitor of $C 5$ activation from the soft tick Ornithodoros moubata. J Immunol 2005, 174:2084-2091.

49. Ribeiro JMC, Schneider M, Guimaraes JA: Purification and characterization of Prolixin S (Nitrophorin 2), the salivary anticoagulant of the blood sucking bug, Rhodnius prolixus. Biochem J 1995, 308:243-249.

50. Ribeiro JM, Silva-Neto MA, Pham VM, Garfield MK, Valenzuela JG: Exploring the sialome of the blood-sucking bug Rhodnius prolixus. Insect Biochem Mol Biol 2004, 34:61-79.

51. Assumpção TC, Francischetti IM, Andersen JF, Schwarz A, Santana JM, Ribeiro JM: An insight into the sialome of the blood-sucking bug Triatoma infestans, a vector of Chagas' disease. Insect Biochem Mol Biol 2008, 38:213-232.

52. Mans BJ, Andersen JF, Francischetti IM, Valenzuela JG, Schwan TG, Pham VM, Garfield MK, Hammer CH, Ribeiro JM: Comparative sialomics between hard and soft ticks: Implications for the evolution of bloodfeeding behavior. Insect Biochem Mol Biol 2008, 38:42-58.

53. Taylor JS, Raes J: Duplication and divergence: the evolution of new genes and old ideas. Annu Rev Genet 2004, 38:615-643.

54. Paesen GC, Adams PL, Harlos K, Nuttall PA, Stuart DI: Tick histaminebinding proteins: isolation, cloning, and three- dimensional structure. Mol Cell 1999, 3:661-671.

55. Paesen GC, Adams PL, Nuttall PA, Stuart DL: Tick histamine-binding proteins: lipocalins with a second binding cavity. Biochim Biophys Acta 2000, 1482:92-101.

56. Ascenzi P, Bocedi A, Bolognesi M, Spallarossa A, Coletta M, De Cristofaro R, Menegatti $\mathrm{E}$ : The bovine basic pancreatic trypsin inhibitor (Kunitz inhibitor): a milestone protein. Curr Protein Pept Sci 2003, 4:231-251.

57. Stoka V, Lenarcic B, Cazzulo JJ, Turk V: Cathepsin $\mathrm{S}$ and cruzipain are inhibited by equistatin from Actinia equina. Biol Chem 1999, 380:589-592.

58. Bocock JP, Edgell CJ, Marr HS, Erickson AH: Human proteoglycan testican1 inhibits the lysosomal cysteine protease cathepsin L. Eur J Biochem 2003, 270:4008-4015

59. Abrahamson M, Alvarez-Fernandez M, Nathanson CM: Cystatins. Biochem Soc Symp 2003, 70:179-199.

60. Arolas JL, Lorenzo J, Rovira A, Castella J, Aviles FX, Sommerhoff CP: A carboxypeptidase inhibitor from the tick Rhipicephalus bursa: isolation, CDNA cloning, recombinant expression, and characterization. J Biol Chem 2005, 280:3441-3448.

61. Iwanaga S, Okada M, Isawa H, Morita A, Yuda M, Chinzei Y: Identification and characterization of novel salivary thrombin inhibitors from the ixodidae tick, Haemaphysalis longicornis. Eur J Biochem 2003, 270:1926-1934.

62. Lai $R$, Takeuchi $H$, Jonczy J, Rees HH, Turner PC: A thrombin inhibitor from the ixodid tick, Amblyomma hebraeum. Gene 2004, 342:243-249.

63. Paesen GC, Siebold C, Harlos K, Peacey MF, Nuttall PA, Stuart DI: A tick protein with a modified Kunitz fold inhibits human tryptase. $J \mathrm{Mol}$ Biol 2007, 368:1172-1186

64. van de Locht A, Stubbs MT, Bode W, Friedrich T, Bollschweiler C, Hoffken W, Huber R: The ornithodorin-thrombin crystal structure, a key to the TAP enigma? Embo J 1996, 15:6011-6017.

65. Narasimhan S, Koski RA, Beaulieu B, Anderson JF, Ramamoorthi N, Kantor F, Cappello M, Fikrig E: A novel family of anticoagulants from the saliva of Ixodes scapularis. Insect Mol Biol 2002, 11:641-650.

66. Francischetti I M, Valenzuela JG, Andersen JF, Mather TN, Ribeiro JM: Ixolaris, a novel recombinant tissue factor pathway inhibitor (TFPI) from the salivary gland of the tick, Ixodes scapularis: identification of factor $\mathrm{X}$ and factor Xa as scaffolds for the inhibition of factor Vlla/tissue factor complex. Blood 2002, 99:3602-3612. 
67. Mans BJ, Louw Al, Neitz AW: Savignygrin, a platelet aggregation inhibitor from the soft tick Ornithodoros savignyi, presents the RGD integrin recognition motif on the Kunitz-BPTI fold. J Biol Chem 2002, 277:21371-21378.

68. Francischetti IM, Mather TN, Ribeiro JM: Penthalaris, a novel recombinant five-Kunitz tissue factor pathway inhibitor (TFPI) from the salivary gland of the tick vector of Lyme disease, Ixodes scapularis. Thromb Haemost 2004, 91:886-898.

69. Mans BJ, Andersen JF, Schwan TG, Ribeiro JM: Characterization of antihemostatic factors in the argasid, Argas monolakensis: Implications for the evolution of blood-feeding in the soft tick family. Insect Biochem $\mathrm{Mol}$ Biol 2008, 38:22-41.

70. Kotsyfakis M, Sa-Nunes A, Francischetti I M, Mather TN, Andersen JF Ribeiro JM: Antiinflammatory and immunosuppressive activity of sialostatin L, a salivary cystatin from the tick Ixodes scapularis. J Biol Chem 2006, 281:26298-26307.

71. Kotsyfakis M, Karim S, Andersen JF, Mather TN, Ribeiro JM: Selective cysteine protease inhibition contributes to blood-feeding success of the tick Ixodes scapularis. J Biol Chem 2007, 282:29256-29263.

72. Kotsyfakis M, Anderson JM, Andersen JF, Calvo E, Francischetti IM, Mather TN, Valenzuela JG, Ribeiro JM: Cutting edge: Immunity against a "silent" salivary antigen of the Lyme vector Ixodes scapularis impairs its ability to feed. J Immunol 2008, 181:5209-5212.

73. Lenarcic B, Turk $V$ : Thyroglobulin type- 1 domains in equistatin inhibit both papain-like cysteine proteinases and cathepsin D. J Biol Chem 1999, 274:563-566.

74. Lenarcic B, Ritonja A, Strukelj B, Turk B, Turk V: Equistatin, a new inhibitor of cysteine proteinases from Actinia equina, is structurally related to thyroglobulin type-1 domain. J Biol Chem 1997, 272:13899-13903.

75. Arolas JL, Popowicz GM, Lorenzo J, Sommerhoff CP, Huber R, Aviles FX, Holak TA: The three-dimensional structures of tick carboxypeptidase inhibitor in complex with $A / B$ carboxypeptidases reveal a novel doubleheaded binding mode. J Mol Biol 2005, 350:489-498.

76. Nakajima C, Imamura S, Konnai S, Yamada S, Nishikado H, Ohashi K, Onuma M: A novel gene encoding a thrombin inhibitory protein in a CDNA library from Haemaphysalis longicornis salivary gland. J Vet Med Sci 2006, 68:447-452.

77. Kazimírová $M$, Jancinová $V$, Petríková $M$, Takác $P$, Labuda $M$, Nosál' R: An inhibitor of thrombin-stimulated blood platelet aggregation from the salivary glands of the hard tick Amblyomma variegatum (Acari: Ixodidae). Exp Appl Acarol 2002, 28:97-105.

78. Schlott B, Wohnert J, Icke C, Hartmann M, Ramachandran R, Guhrs KH, Glusa E, Flemming J, Gorlach M, Grosse F, Ohlenschläger O: Interaction of Kazal-type inhibitor domains with serine proteinases: biochemical and structural studies. J Mol Biol 2002, 318:533-546.

79. Valenzuela JG, Francischetti IMB, Pham VM, Garfield MK, Mather TN, Ribeiro JMC: Exploring the sialome of the tick, Ixodes scapularis. J Exp Biol 2002, 205:2843-2864

80. Murray D, Ben-Tal N, Honig B, McLaughlin S: Electrostatic interaction of myristoylated proteins with membranes: simple physics, complicated biology. Structure 1997, 5:985-989.

81. Macia E, Paris S, Chabre M: Binding of the $\mathrm{PH}$ and polybasic C-terminal domains of ARNO to phosphoinositides and to acidic lipids. Biochemistry 2000, 39:5893-58901.

82. Huang TF, Niewriarowski S: Disintegrins: The naturally-occurring antagonists of platelet fibrinogen receptors. J Toxicol Toxin Rev 1994, 13:253-273.

83. Da Silva M, Lucena S, Aguilar I, Rodríguez-Acosta A, Salazar AM, Sánchez EE, Girón ME, Carvajal Z, Arocha-Piñango CL, Guerrero B: Anti-platelet effect of cumanastatin 1, a disintegrin isolated from venom of South American Crotalus rattlesnake. Thromb Res 2009, 123:731-739.

84. Xu X, Yang H, Ma D, Wu J, Wang Y, Song Y, Wang X, Lu Y, Yang J, Lai R Toward an understanding of the molecular mechanism for successful blood feeding by coupling proteomics analysis with pharmacological testing of horsefly salivary glands. Mol Cell Proteomics 2008, 7:582-590.

85. Reiss K, Ludwig A, Saftig P: Breaking up the tie: disintegrin-like metalloproteinases as regulators of cell migration in inflammation and invasion. Pharmacol Ther 2006, 111:985-1006.

86. Crawford HC, Dempsey PJ, Brown G, Adam L, Moss ML: ADAM10 as a therapeutic target for cancer and inflammation. Curr Pharm Des 2009, 15:2288-2299
87. Calvete JJ, Marcinkiewicz C, Sanz L: KTS and RTS-disintegrins: antiangiogenic viper venom peptides specifically targeting the alpha 1 beta 1 integrin. Curr Pharm Des 2007, 13:2853-2859.

88. Hati R, Mitra P, Sarker S, Bhattacharyya KK: Snake venom hemorrhagins. Crit Rev Toxicol 1999, 29:1-19.

89. Wikel SK: Influence of Dermacentor andersoni infestation on lymphocyte responsiveness to mitogens. Ann Trop Med Parasitol 1982, 76:627-632.

90. Ramachandra RN, Wikel SK: Modulation of host-immune responses by ticks (Acari: Ixodidae): effect of salivary gland extracts on host macrophages and lymphocyte cytokine production. J Med Entomol 1992, 29:818-826.

91. Wikel SK, Ramachandra RN, Bergman DK: Tick-induced modulation of the host immune response. Int J Parasitol 1994, 24:59-66.

92. Hajnicka V, Vancova I, Kocakova P, Slovak M, Gasperik J, Slavikova M Hails RS, Labuda M, Nuttall PA: Manipulation of host cytokine network by ticks: a potential gateway for pathogen transmission. Parasitology 2005, 130:333-342.

93. Hovius JW, Levi M, Fikrig E: Salivating for knowledge: potential pharmacological agents in tick saliva. PLoS Med 2008, 5:e43.

94. Oliveira CJ, Cavassani KA, Moré DD, Garlet GP, Aliberti JC, Silva JS, Ferreira BR: Tick saliva inhibits the chemotactic function of MIP-1alpha and selectively impairs chemotaxis of immature dendritic cells by downregulating cell-surface CCR5. Int J Parasitol 2008, 38:705-716.

95. Frauenschuh A, Power CA, Deruaz M, Ferreira BR, Silva JS, Teixeira MM, Dias JM, Martin T, Wells TN, Proudfoot AE: Molecular cloning and characterization of a highly selective chemokine-binding protein from the tick Rhipicephalus sanguineus. J Biol Chem 2007, 282:27250-27258.

96. Deruaz M, Frauenschuh A, Alessandri AL, Dias JM, Coelho FM, Russo RC, Ferreira BR, Graham GJ, Shaw JP, Wells TN, Teixeira MM, Power CA, Proudfoot AE: Ticks produce highly selective chemokine binding proteins with antiinflammatory activity. J Exp Med 2008, 205:2019-2031.

97. Alarcon-Chaidez FJ, Muller-Doblies UU, Wikel S: Characterization of a recombinant immunomodulatory protein from the salivary glands of Dermacentor andersoni. Parasite Immunol 2003, 25:69-77.

98. Konnai S, Nakajima C, Imamura S, Yamada S, Nishikado H, Kodama M, Onuma M, Ohashi K: Suppression of cell proliferation and cytokine expression by HL-p36, a tick salivary gland-derived protein of Haemaphysalis longicornis. Immunology 2009, 126:209-219.

99. Bulet $P$, Stocklin R, Menin L: Anti-microbial peptides: from invertebrates to vertebrates. Immunol Rev 2004, 198:169-184.

100. Torres AM, Kuchel PW: The beta-defensin-fold family of polypeptides. Toxicon 2004, 44:581-588.

101. Couillault C, Pujol N, Reboul J, Sabatier L, Guichou JF, Kohara Y, Ewbank JJ: TLR-independent control of innate immunity in Caenorhabditis elegans by the TIR domain adaptor protein TIR-1, an ortholog of human SARM. Nat Immunol 2004, 5:488-494.

102. Andersen SO, Peter MG, Roepstorff P: Cuticular sclerotization in insects. Comp Biochem Physiol B 1996, 113:698-705.

103. Sugumaran M: Unified mechanism for sclerotization of insect cuticle. Adv Insect Physiol 1998, 27:227-334.

104. Kemp DH, Stone BF, Binnington KC: Tick attachment and feeding: Role of mouthparts, feeding apparatus, salivary gland secretions and the host response. Physiology of ticks Pergamon Press, Ltd, OxfordObenchain FD, Galun R 1982, 119-168.

105. Needham GR, Jaworski DC, Simmen FA, Sherif N, Muller MT: Characterization of ixodid tick salivary-gland gene products, using recombinant DNA technology. Exp Appl Acarol 1989, 7:21-32.

106. Jaworski DC, Muller MT, Simmen FA, Needham GR: Amblyomma americanum: identification of tick salivary gland antigens from unfed and early feeding females with comparisons to Ixodes dammini and Dermacentor variabilis. Exp Parasitol 1990, 70:217-226.

107. Bishop R, Lambson B, Wells C, Pandit P, Osaso J, Nkonge C, Morzaria S, Musoke A, Nene V: A cement protein of the tick Rhipicephalus appendiculatus, located in the secretory e cell granules of the type III salivary gland acini, induces strong antibody responses in cattle. Int $J$ Parasitol 2002, 32:833-842.

108. Trimnell AR, Davies GM, Lissina O, Hails RS, Nuttall PA: A cross-reactive tick cement antigen is a candidate broad-spectrum tick vaccine. Vaccine 2005, 23:4329-4341.

109. Fukuda M: Roles of mucin-type O-glycans in cell adhesion. Biochim Biophys Acta 2002, 1573:394-405. 
110. Hang HC, Bertozzi CR: The chemistry and biology of mucin-type O-linked glycosylation. Bioorg Med Chem 2005, 13:5021-5034.

111. Crosby M, Goodman J, Strelets V, Zhang P, Gelbart W, FlyBase Consortium: Flybase: genomes by the dozen. Nucleic Acids Res 2007, 35:D486-D491.

112. Havlíková S, Roller L, Koci J, Trimnell AR, Kazimírová M, Klempa B, Nuttall PA: Functional role of $64 \mathrm{P}$, the candidate transmission-blocking vaccine antigen from the tick, Rhipicephalus appendiculatus. Int J Parasitol 2009, 39:1485-1494.

113. Mazet F, Shimeld SM: Gene duplication and divergence in the early evolution ofvertebrates. Curr Opin Genet Dev 2002, 12:393-396.

doi:10.1186/1471-2164-11-450

Cite this article as: Anatriello et al: An insight into the

sialotranscriptome of the brown dog tick, Rhipicephalus sanguineus. BMC Genomics 2010 11:450.

Submit your next manuscript to BioMed Central and take full advantage of:

- Convenient online submission

- Thorough peer review

- No space constraints or color figure charges

- Immediate publication on acceptance

- Inclusion in PubMed, CAS, Scopus and Google Scholar

- Research which is freely available for redistribution

Submit your manuscript at www.biomedcentral.com/submit
C Biomed Central 